\title{
Home Energy Management System for a domestic load center using Artificial Neural Networks towards Energy Integration
}

\author{
M. Pratapa Raju, A. Jaya Laxmi
}

\begin{abstract}
This paper titled 'Home Energy Management System (HEMS) for a domestic load center using Artificial Neural Networks towards Energy Integration' focuses on implementing intelligent integration of Distribution Generation Systems (DGS) for domestic load. The proposed energy integration by HEMS, is executed by implementing a Load Management Algorithm (LMA), which functions based on ANN forecast models. Demand Side Management (DSM) techniques are the back bone for LMA proposed in this paper. Historical temperature data and electrical load data of a domestic load center at Municipality of Birmingham, City of Alabama, USA, is considered to implement the proposed LMA. Two subroutine programs/algorithms are designed to implement the proposed LMA. First is of implementing Load Priority Techniques, to assign Load Priority for the loads for the hour based on the temperature forecast. Temperature forecast is done using Nonlinear Auto Regression with Exogenous Inputs (NARX) ANN time series model. And this is termed as Load Priority Assignment Algorithm (LPAA). Second is of predicting Threshold Power $\left(P_{T h}\right)$ for the hour as per load priority assigned by LPAA, this is termed as estimation of $P_{T h}$. Big data driven Nonlinear Auto Regression with Exogenous Inputs (NARX) Neural Net based temperature forecasting model is implemented and used to assign hourly priority for all the appliances/loads. Big data driven Artificial Neural Network (ANN) based load power forecasting model is implemented and used to predict hourly $P_{T w}$ LMA proposed for HEMS is implemented with step by step comparison of current load demand with $P_{T h}$ and transferring the loads between the energy sources, according to the load priority assignment from LPAA. Proposed LMA based HEMS contributes to enhance the penetration of nonconventional DGS into domestic load sector. Simulation of proposed HEMS is implemented in MATLAB-Simulink environment using MATLAB 2018b. Simulation model is embedded into target hardware: Arduino 2560 by enabling serial communication protocols between MATLAB-SIMULINK and ARDUINO. Hence the experimental setup of HEMS would be functional to prove simulation results and to transfer the loads in real time. Working Hardware model of the HEMS at domestic load center is fabricated using simple and cost effective components such as current sensor ACS712, Arduino Mega 2560, relays and relay driver circuit.
\end{abstract}

Keywords: Home Energy Management System (HEMS), Load Management Algorithm (LMA), Load Priority Assignment Algorithm (LPAA), Demand Side Management Techniques (DSM), Artificial Neural Networks.

Revised Manuscript Received on November 25, 2019.

* Correspondence Author

M. Pratapa Raju, Electrical Electronics Engineering, JNTUH college of Engineering, JNTUH, Hyderabad, India. Email: raj4u.pe@gmail.com.

Dr. A Jaya Laxmi, Electrical Electronics Engineering, JNTUH college of Engineering, JNTUH, Hyderabad, India. Email: aj11994 @yahoo.co.in

\section{INTRODUCTION}

As per the monthly energy details recorded by U.S Energy Information Administration (EIA), residential energy consumption owes to a majority share of $38 \%$ of the entire electricity consumption of the country [1]. In addition to the fact that the residential load is a huge shareholder in energy market, it is also most unpredictable which is most influencing in planning and managing the electrical energy production. In late 1970's DSM Techniques were introduced to the energy sector to manage the load demand and supply with certain techniques. Ever increasing investment in demand side management with more emphasis on peak reduction techniques has taken place for effective load management [2], [3].

To balance the ever growing demand at residential load section, DGSs have been a promising measure to meet the demand and balance the gap between supply and demand. DGSs are the small generators or sources connected in line with distribution network or to the consumer meter [4]. DGSs have gained popularity since the conventional grid failure in 2003 in US. Low investment and operating cost has been another driving force for DGS's rapid growth in electric grid. Integration of these small power generators (conventional and non-conventional) such as micro turbine generator and solar cells eventually meet the needs of the consumer, with high voltage profile and stability of the distribution system. The aspects affected by the introduction of DGS units into the existing distribution network are voltage control, power quality, protection system, fault level, grid losses [5]. Integration of these DGSs available at a residential load center is very much preferred to utilize the energy optimally. In integrating the energy sources available at load center, HEMS can play a vital role. It was in 1990 the first ever energy management system with its complete architecture was introduced, to manage the domestic load consumption [6]. In the latest era of smart grid HEMS are the most common systems in use when compared to EMU. Both systems work for the same objective but with different architecture. In smart grid environment HEMS is an essential component at the residential load centers. A lot of progress is achieved in hardware designs with design simulations, which prove that HEMS is pathway to the future smart grid environment [7], [8]. DSM Techniques are also implemented in HEMS to effectively manage the loads using intelligent billing and trading system [9]. HEMS also incorporates the future prediction algorithms, to plan for the load priority and load scheduling [10]. In 2013, hardware design of HEMS is proposed with dynamic price response [11]. It is obvious that the HEMS deigned is to perform

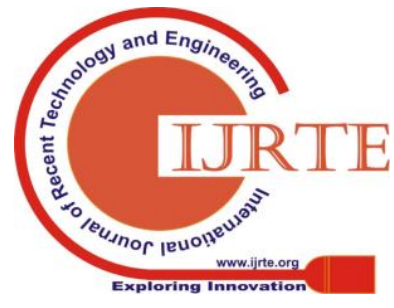




\section{Home Energy Management System for a domestic load center using Artificial Neural Networks towards Energy Integration}

load management, is bound to have an algorithm to perform the tasks, such as dynamic pricing, intelligent billing etc. Most of the algorithms proposed are either from the foundations of DSM or from Demand Response (DR). DR is one of the approaches of DSM implementation, it has three types of automation levels to implement various techniques of DSM [12]. In 2012, HEM algorithm is presented with presumed load priority at the load center, as per consumer comfort levels. Different control strategies are also presented for different loads [13]. In 2012, real time household priority scheduling algorithm is proposed, which focuses on offline appliance scheduling and online appliance scheduling. Load priority of the appliances is determined based on hour by hour weather forecast. As per the assigned load priority, load scheduling is done based on predicted nonconventional power at the load center [14]. In 2017, a novel load management algorithm based on load priority and peak clipping techniques of DSM is presented to integrate the conventional and nonconventional sources of energy [15]. In the context of energy management for smart cities, home energy management as a service is presented with an effect of peak reduction, embedded with Q-learning method which is self-learning and predictive [16]. In this paper authors have considered Internet of Things (IOT) for the implementation of energy management. Although there is a peak power reduction achieved in [16], it is not fully based on DSM Techniques. The capabilities of HEMS can be extended to even integrate the conventional and nonconventional DGSs installed at the load center by implementing DSM Techniques and intelligent algorithms.

This paper presents an improved HEMS, embedded with ANN- based LMA by applying DSM Techniques at every step of implementation. The work presented in this paper implements similar load priority algorithm as introduced in [14], but using ANN based predictive algorithms. The work is carried out using the hardware support package of MATLAB 2018b, using simple and low cost ARDUINO and other devices. This makes the proposed HEMS novel and unique.

\section{ARCHITECTURE OF HEMS}

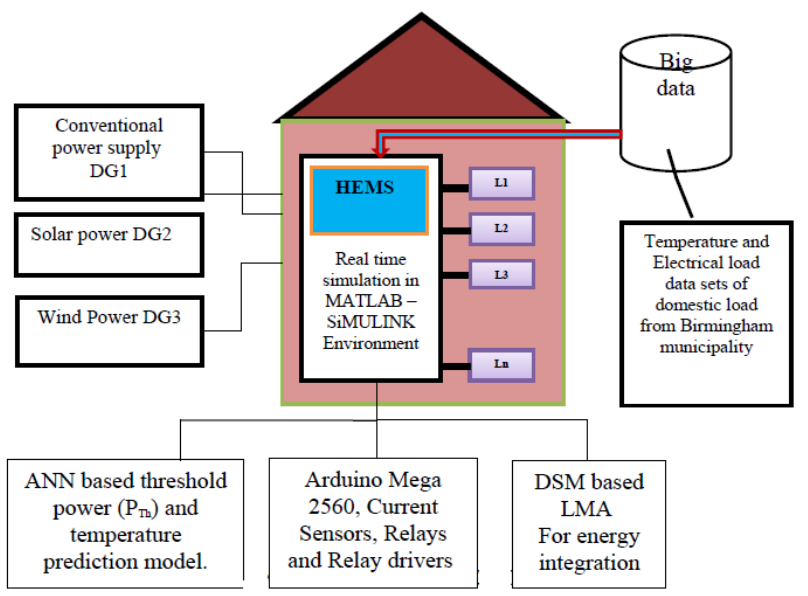

Fig.1. Proposed HEMS at a domestic load center

The basic architecture of HEMS with all essential sections is presented in figure 1 . Its key role is to transfer domestic loads between the different sources, which contributes to energy integration. Conventional and nonconventional source facilities are assumed to be present at the domestic load center. In smart city environment, HEMS is an essential setup at any load center to manage the load demand. The hardware setup presented in this paper is fabricated with cost effective devices such as Arduino 2560 and ACS 712 etc. HEMS present at the load center is an intermediate system between available source and loads, for switching loads between sources. Big data mentioned in the architecture indicates that the HEMS learn from the data and takes decision of load transfer between the sources. Hence the energy integration can be made more effective.

\section{METHODOLOGY OF LOAD MANAGEMENT FOR THE DOMESTIC LOAD CENTER}

DSM based LMA proposed in this paper is implemented in four stages which is as shown in figure 2. First stage is about collecting and arranging the electrical load data, historical weather data collected to deal with forecast. There are two subroutine algorithms/programs and one main Algorithm and all of them run simultaneously to enable effective energy integration at the load center. The different stages are: Stage 1 compiles, analyzes big data and makes it ready for predictions. Stage 2 executes LPAA which essentially assigns priority to all the loads. Stage 3 estimates $\mathrm{P}_{\mathrm{Th}}$ for the hour. And stage 4 executes LMA towards energy integration. Based on the results obtained in first two stages direct load scheduling can be done at stage 3 (without moving to stage 4). There are many papers presented on direct load scheduling but the work presented in this paper moves further to stage 4 and implements DSM based LMA using future predictions.

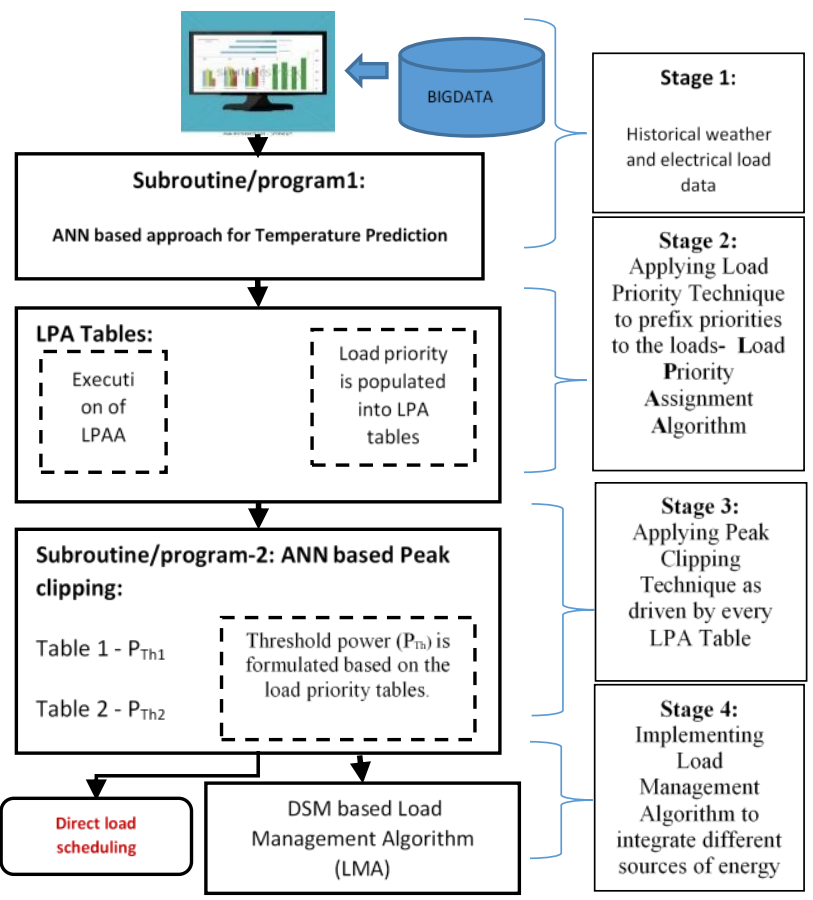

Fig.2. Architecture and flow of Energy Management in smart home 


\section{STAGES OF METHODOLOGY}

\section{A. Stage-1: Load Data Collection and Analysis of Domestic Load Center}

As the first step towards the implementation of the proposed system, historical temperature and simulated hourly electrical load data for one year of a domestic load center located at Birmingham municipality, city of Alabama, USA, is considered. NARX model and ANN based prediction models are implemented using the big data collected of the load center. Figure 2 presents the complete load profile of domestic load center. Hourly historical temperature data of the above specified location is collected from public websites and presented in the subsequent sections. A total of 8760 data samples of twelve load sections and temperature data of the load center is collected and used to implement ANN prediction model.

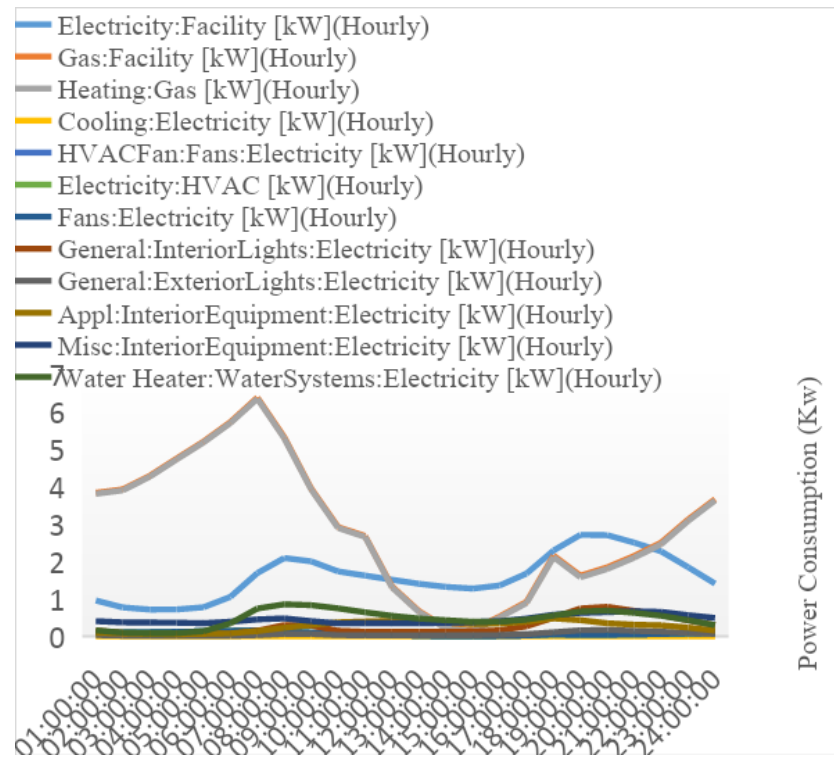

Fig.3. Loading profile of all appliances at the load center

\section{B. Stage-2: Load Priority Assignment Algorithm}

The main goal of DSM is to enable the consumer to use less energy during peak hours or to shift the time of use of energy to off-peak times such as night time and weekends. Out of the many DSM techniques, this paper considers only two techniques namely load priority technique and peak clipping technique. A new approach of implementing load priority technique for the effective priority assignment for the loads of the load center is presented in this paper. This paper emphasizes LPAA for the loads based on forecasted temperature and non-conventional power available at domestic load center. All the different appliances existing at load center are classified into three categories based on the mode of energy consumption of appliances. The three categories mentioned are appliances with real time energy consumption, appliances with periodic non-real time energy consumption and appliances with non-periodic, non-real time energy consumption modes. Out of all the different loads present at domestic load center heating and cooling loads are considered to be heavy loads in terms of energy consumption. The proposed algorithm orderly assigns priorities to these loads, with the help of NARX model based prediction [17]. The LPAA proposed in this paper is fundamentally based on [14], but an additional conditional priority assignment for the lighting loads is added. As presented in figure 4, LPAA has three different sections. First section is of load priority assignment for heating loads based on temperature prediction. Second section is of load priority assignment for cooling loads based temperature prediction. Third section is about load priority assignment for exterior and interior lighting loads based on the availability of non-conventional power sources. Flow chart of the LPAA is presented in figure 4, and steps of the algorithm are explained in the subsequent paragraph.

Steps of LPA Algorithm:

Control starts from the first section with a preexisting output matrix (hourly temperature values) of NARX temperature prediction (forecast) model, which provides (24 hours) day ahead forecasted values of the temperature, denoted with $\mathrm{T}_{\mathrm{f}}$. Throughout the algorithm, forecasted temperature for the specific hour is compared with preset temperature limits. Different Preset temperature values are defined for both heating loads and cooling loads. For heating loads the preset temperature values considered are $\mathrm{T}_{\max 1}, \mathrm{~T}_{\min 1}$ and for cooling loads $\mathrm{T}_{\max 2}$ and $\mathrm{T}_{\min 2}$. The algorithm proposed considers four different categories of priorities for the priority assignment of loads namely, higher priority $\left(\mathrm{H}_{1}, \mathrm{H}_{2}\right)$, medium priority $\left(\mathrm{M}_{1}, \mathrm{M}_{2}\right)$, lower priority $\left(\mathrm{LW}_{1}, \mathrm{LW}_{2}\right)$ and least priority $\left(\mathrm{LS}_{1}, \mathrm{LS}_{2}\right) . \mathrm{H}_{1}, \mathrm{H}_{2}$ and $\mathrm{H}_{3}$ are to assign orderly priority, if there is more than one load active at the load center for that hour. The same can be adapted for other category of priorities as well.

1. In the first section of LPA for heating loads: Temperature $\left(T_{f}\right)$ for hour from output forecast values of NARX temperature prediction model, is compared with preset temperature limits. If predicted $\mathrm{T}_{\mathrm{f}}$ is more than $\mathrm{T}_{\max 1}$, then assign priority for the heating load as $\mathrm{LW}_{2}$. Else control moves further to compare $\mathrm{T}_{\mathrm{f}}$ with other set of preset temperature limits.

2. If $\mathrm{T}_{\max 1}>\mathrm{T}_{\mathrm{f}}>\mathrm{T}_{\min 1}$, then assign priority for the heating load as $\mathbf{M}_{2}$, else control moves further to compare the predicted $\mathrm{T}_{\mathrm{f}}$ with present limits of temperature.

3. If $\mathrm{T}_{\mathrm{f}}<=\mathrm{T}_{\min 1}$, then assign priority for the heating load as $\mathrm{H}_{2}$, else control moves further and assigns a priority to the Heating load which is based on the instruction from the consumer. Else control moves further, to follow the loading instructions from user.

4. In the second section of load priority for cooling loads: $T_{f}$ for hour from output forecast values of prediction model is compared with preset temperature limits. If $\mathrm{T}_{\mathrm{f}}$ is less than $\mathrm{T}_{\min 2}$, then assign priority for the cooling load as $\mathrm{LW}_{1}$. Else control moves further to compare $\mathrm{T}_{\mathrm{f}}$ with next preset limits of the temperature.

5. If $\mathrm{T}_{\max 2}>\mathrm{T}_{\mathrm{f}}>\mathrm{T}_{\min 2}$, then assign priority for the cooling load as $\mathrm{M}_{2}$, Else control moves further to compare $\mathrm{T}_{\mathrm{f}}$ with preset limits of temperature.

6. If $\mathrm{T}_{\mathrm{f}}>=\mathrm{T}_{\max 2}$, then assign priority for the cooling load as $\mathrm{H}_{1}$, Else control moves further and assigns a priority to the Heating load as per the instruction of the consumer. In each step of the algorithm the LPA table is populated with the data of priority assignment such as $\mathrm{LW}_{1}, \mathrm{M}_{1}, \mathrm{H}_{1}$ based on which the loads are operated by the HEMS. Else control moves further, to follow the loading instructions from user.

7. In third section of load priority for lighting loads: Non- conventional power $\left(\mathrm{P}_{\mathrm{fNC}}\right)$ from the prediction model is compared with 


\section{Home Energy Management System for a domestic load center using Artificial Neural Networks towards Energy Integration}

preset power limits. If the predicted $\mathrm{P}_{\mathrm{fNC}}>=\mathrm{P}_{\max }$, then assign $\mathrm{LS}_{1}, \mathrm{LS}_{2}$ priorities for the interior and exterior lighting loads. Final LPA tables Table-1, Table-2, Table-3 can be populated with load priority assignment for all the loads as derived from section one, two and three. Else control moves further.
8. If $\mathrm{P}_{\max }>\mathrm{P}_{\mathrm{fNC}}>0.7 \mathrm{P}_{\max }$, then lighting loads are assigned with $\mathrm{LW}_{1}, \mathrm{LW}_{2}$, priorities. Final LPA Tables Table-4, Table -5 , Table -6 can be populated with load priority assignment for all the loads as derived from section one, two and three. Else control moves further.

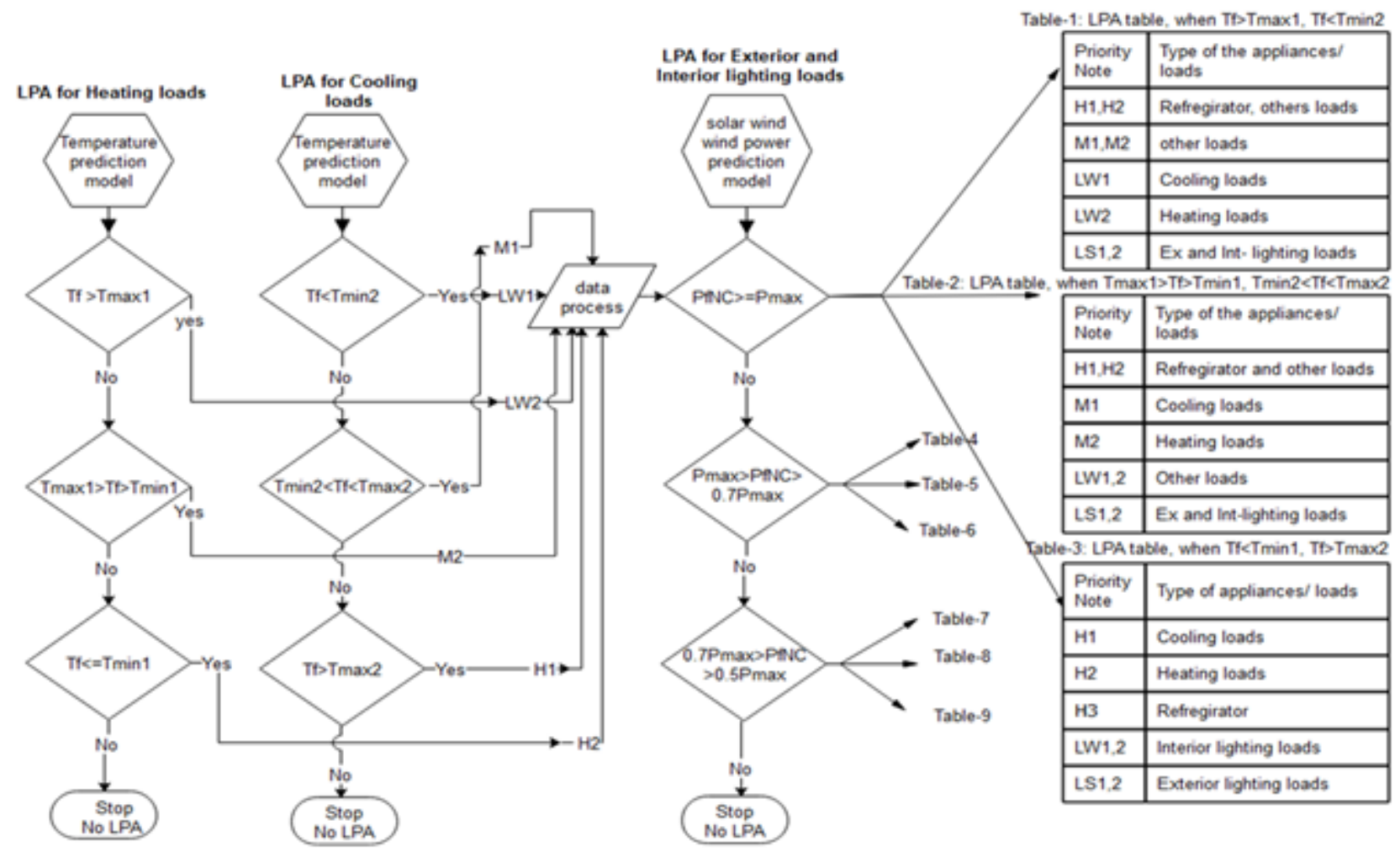

Fig.4. Load Priority Assignment Algorithm

9. If $0.7 \mathrm{Pmax}>\mathrm{PfNC}>0.5 \mathrm{Pmax}$, then lighting loads are assigned with M1, M2 priorities. Final LPA Tables Table-7, Table-8, Table-9 are populated with load priority assignment for all the loads as derived from section one, two and three. Else control moves further, to follow the loading instructions from user.

To summarize the algorithm, as an outcome of three sections of LPAA process, LPA table is populated with the data of priority assignment such as $\mathrm{LW}_{2}, \mathrm{M}_{2}, \mathrm{H}_{2}$, based on which the loads are operated by HEMS. Eventually only one LPA table results out of nine possible LPA tables.

\section{Stage 3: Estimation of $\mathbf{P}_{\mathrm{Th}}$ by applying Peak clipping Technique}

Peak clipping is one of the best techniques adapted ever in the concept of DSM. The proposed work in this paper implements peak clipping technique after the implementation of LPAA. LPA tables are derived by the successful implementation of LPAA. Data of load priority populated into LPA tables is sorted to make effective equation of $\mathrm{P}_{\mathrm{Th}}$. Equations (1) to (5) presented in figure 5, represent $\mathrm{P}_{\mathrm{Th}}$ equations derived from the LPA tables. As per the LPA table, subtracting lower and least priority loads from $\mathrm{P}_{\mathrm{T}}$ could result in possible $\mathrm{P}_{\mathrm{Th}}$, which is used for LMA. $\mathrm{P}_{\mathrm{Th}}$ (peak clipping) changes as per LPT.

$\mathrm{P}_{\mathrm{Th}}$ is total load power after clipping the peak, so it will be always less than $\mathrm{P}_{\mathrm{T}}$. If there is no load assigned with lower or least priority then $\mathrm{P}_{\mathrm{Th}}$ could even be equal to $\mathrm{P}_{\mathrm{T}}$, as mentioned in equation (5). $\mathrm{P}_{\mathrm{Th}}$ formally depends on $\mathrm{P}_{\mathrm{T}}$, lower and least priority load magnitudes. $\mathrm{P}_{\mathrm{T}}$ is forecasted total power output resulted from ANN prediction model
[18]. Least and lower priority load magnitudes depend on LPT which results from LPAA. This paper executes LMA with $\mathrm{P}_{\mathrm{Th}}$ as per equation (4) to enable energy integration at the load center.

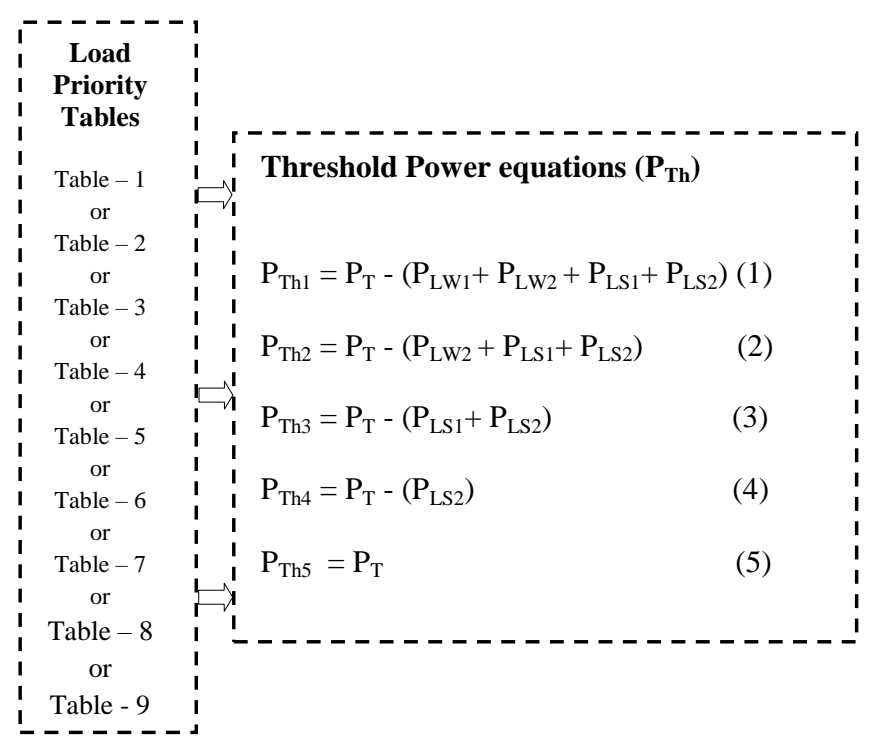

Fig.5. Load Priority Assignment Algorithm 


\section{Stage 4: Load Management Algorithm}

LMA proposed in this paper enables the integration of available DGSs at the load center. In every step of the LMA implementation DSM techniques such as load priority and peak clipping are applied for the integration of DGS. Integration of DGS mainly aims on increasing the penetration of non-conventional energy sources available at the load center. The LMA proposed in this paper brings a renewable DGS into the existing network, and this would lead to certain physical impacts on the existing network. As the active power feeds from DG units connected to distribution networks increases the voltage increases at the connection point and along the whole feeder. This voltage rise becomes an issue when the active power produced by DG units exceeds the active power consumed by the loads. The voltage limit may rise beyond the maximum limit set by the substation [5]. The proposed algorithm does not focus on reducing current rise, voltage rise and power injections by the DGS to achieve healthy integration of DGSs. But this algorithm brings non-conventional DGSs into the existing Distribution Network with rightly assigned load priority to all the loads, to achieve the optimal utilization of conventional sources of energy.

There are various methods considering independent variables, to model the load consumption at residential loads. As per JV Patero and PD Lund [19], it is quite convenient to take the load power consumption model based on its consumption cycle. The consumption cycle is initiated by the starting function using the starting probability function $\mathrm{P}_{\text {start }}$.

$$
\begin{aligned}
& P_{\text {start }}\left(A, K, \Delta T_{\text {step }}, \Delta d, H, D\right) \\
& =P_{\text {season }}(A, K) P_{H}(A, H, D) f(A, D) P_{\text {step }}(\Delta T \text { step }) P_{\text {social }}(\Delta d)
\end{aligned}
$$

There are many notations mentioned in equation (6), and they are; $P_{\text {season }}$ : seasonal probability factor, $P_{\mathrm{H}}$ : hourly probability factor, $f$ : mean daily starting frequency, Pstep: step size scaling factor, $P_{\text {social }}:$ social random factor, $A$ : load appliance, $K$ : week of the year, $H$ : hour of the day, $D$ : day of the day, $\Delta$ Tstep: computational time step, $\Delta d$ : standard deviation for $P_{\text {social }}, P_{\text {start }}$ is defined for each time step, which is always confined to 0 or 1 . As per equation (6), load estimation depends on the probability of the start of the load, which basically depends on $P_{\text {season }}$. $P_{\text {season }}$ accounts to the climatic changes, such as temperature, humidity, wind, visibility. Review on Power consumption prediction published in [20], indicating research findings of 22 papers; Out of which 13 considered only historical data of temperature as input variable for prediction, 3 considered historical temperature and humidity data, 3 used additional weather parameters such as wind etc., and 3 used only load parameters. Hence, this paper also implements power prediction model with only the co load variables with time stamp as an input to train ANN model. Results of ANN training and testing, prediction of $\mathrm{P}_{\mathrm{T}}$ and estimation of $\mathrm{P}_{\mathrm{Th}}$ are presented here in the subsequent section.

$$
\begin{aligned}
\mathrm{P}_{T n} & =\sum_{\substack{i=1 \\
p-1, n=p}}^{p} P_{i} \\
\mathrm{P}_{T(n-1)} & =\sum_{i=1} P_{i}
\end{aligned}
$$

$$
\mathrm{P}_{T(n-p)}=\sum_{i=1}^{p-n, n=p} P_{i}
$$

Equations (7) to (9) are formulated to estimate total power $\left(\mathrm{P}_{\mathrm{Tn}}\right)$ for the hour based on which proposed algorithm is executed. $\mathrm{P}_{\mathrm{T}(\mathrm{n}-1)}$ to $\mathrm{P}_{\mathrm{T}(\mathrm{n}-\mathrm{p})}$ are being considered as a part of peak clipping with respect to load priority assignment. Equation (7) represents power consumption from the real time loading of all ' $n$ ' loads having ' $p$ ' priorities assigned. Equation (8) represents power consumption by the loads with priorities from $\mathrm{i}=1$ to $\mathrm{P}-1$ (excluding the least priority load). Equation (9) represents power consumption by the loads from $\mathrm{i}=1$ to $\mathrm{i}=0$ (excluding all the loads except highest priority of 1$)(\mathrm{p}=\mathrm{n})$, in the last step of the algorithm, with ' $n$ ' loads having ' $p$ ' priorities.

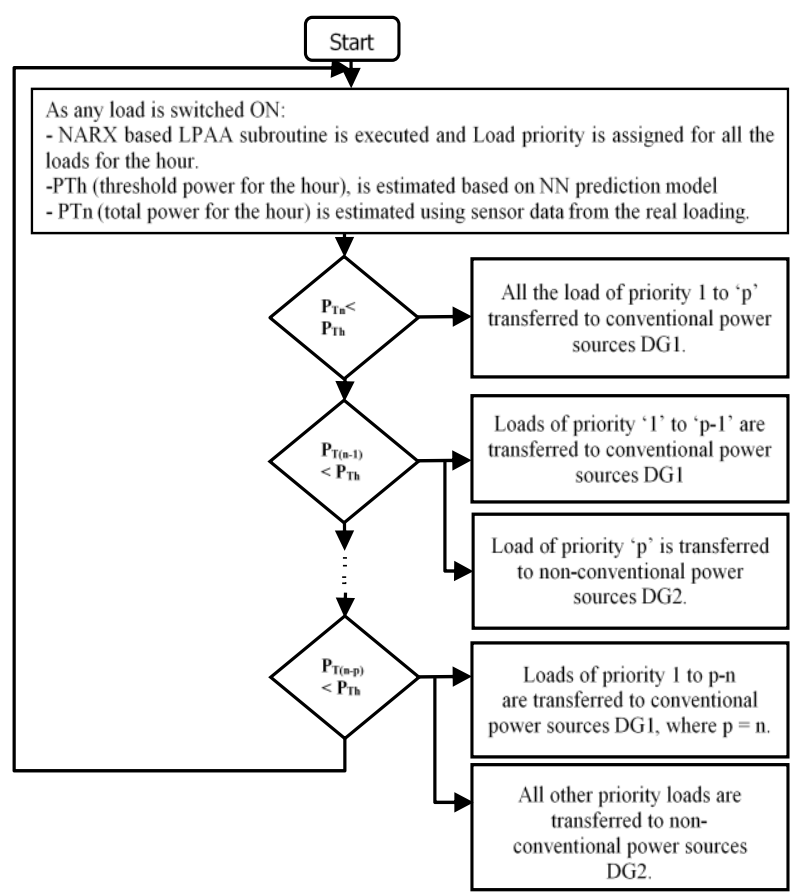

Fig.6. Flow chart of Load Management Algorithm (LMA)

Steps of Load Management Algorithm:

The algorithm starts, by invoking: LPT from LPAA, Threshold Power $\left(\mathrm{P}_{\mathrm{Th}}\right)$ values for all the hours from $\mathrm{P}_{\mathrm{Th}}$ estimation block and real Power $\left(\mathrm{P}_{\mathrm{Tn}}\right)$ consumption of all the loads estimated using sensory system.

Step-1: When user turns any appliance active/on, total power at the moment (read through sensory system) $\mathrm{P}_{T n}$ is compared with estimated $\mathrm{P}_{\text {Th }}$ based on ANN results. If $\mathrm{P}_{T n}$ is less than $\mathrm{P}_{\mathrm{Th}}$ then all loads of priority from $\mathrm{P}_{1}$ to $\mathrm{P}_{\mathrm{p}}$ are transferred to conventional $\mathrm{DGS}_{1}$. Else the control moves to next step.

Step-2: $\mathrm{P}_{\mathrm{T}(\mathrm{n}-1)}$ is compared with $\mathrm{P}_{\mathrm{Th}}: \mathrm{P}_{\mathrm{T}(\mathrm{n}-1)}$ is the total power sensed at the moment excluding least priority load $\mathrm{P}_{\mathrm{n}}$. If $\mathrm{P}_{\mathrm{T}(\mathrm{n}-1)}$ is less than $\mathrm{P}_{\mathrm{Th}}$, loads having the priorities $\mathrm{P}_{1}$ to $\mathrm{P}_{(\mathrm{p}-}$ 1) are transferred to conventional $\mathrm{DGS}_{1}$ and load having priority $\mathrm{P}_{\mathrm{p}}$ is transferred to non-conventional $\mathrm{DGS}_{2}$. Else the control moves to next step.

Step-3: $\mathrm{P}_{\mathrm{T}(\mathrm{n}-2)}$ is compared with $\mathrm{P}_{\mathrm{Th}}$, if $\mathrm{P}_{\mathrm{T}(\mathrm{n}-2)}$ is less than $\mathrm{P}_{\text {Th }}$, loads having priorities $\mathrm{P}_{1}$ to $\mathrm{P}_{(\mathrm{p}-2)}$ are transferred to conventional DGS $\mathrm{D}_{1}$ and loads having priorities $\mathrm{P}_{\mathrm{p}-1}$ and $\mathrm{P}_{\mathrm{p}}$ are transferred to non-conventional $\mathrm{DGS}_{2}$. Else the control moves to next step.

The algorithm proceeds to compare $\mathrm{P}_{\mathrm{Tn}}$ with $\mathrm{P}_{\mathrm{Th}}$ until the 


\section{Home Energy Management System for a domestic load center using Artificial Neural Networks towards Energy Integration}

control moves to the highest priority load $\mathrm{P}_{1}$ by transferring least, lower and medium priority loads to non-conventional $\mathrm{DGS}_{2}$. At the end the highest priority load is transferred to conventional DGS . $_{1}$

The main aim of the algorithm to increase the penetration of non-conventional energy sources is served, as the loads are transferred between conventional and nonconventional sources as per their priorities.

\section{SIMULATION OF THE PROPOSED HEMS IMPLEMENTED IN MATLAB/SIMULINK ENVIRONMENT}

HEMS proposed in this paper is simulated in MATLAB-SIMULINK environment. A SIMULINK model is developed with MATLAB functions and NN Simulink model to predict $t_{f}$ and $\mathrm{P}_{\mathrm{T}}$, to execute LPAA and LMAs successfully towards energy integration. As mentioned in the earlier sections this paper proposes two ANN based prediction models, one to predict temperature and the other to predict total power demand. First prediction model is of NARX model and is run once at the 0th hour of the day, which results in the temperature predicted data throughout the day. But the second one generates the value of $\mathrm{P}_{\mathrm{T}}$ forecast along with time of the simulation of the model. HEMS model is first run in internal mode to be sure of its performance and then will be run in external mode by changing the simulation settings and selecting the hardware support being used. In external mode, MATLABSIMULINK supporting packages generate a compatible code and run it on the Arduino 2560 (Micro controller). Arduino 2560 is chosen because serial communication between SIMULINK and Arduino is not only easy but also moderately faster. The ability of Arduino to handle more I/O devices makes it unique over other cost effective micro controller units. We have used five ACS 712 current sensors to sense the current and $12 \mathrm{~V}, 5 \mathrm{~A}$ single and double channel relays to switch loads and transfer them from one to another DGS. MCBs of 5A rating are used to protect the system under current shoot ups. Simulation and hardware results are presented in this section, to demonstrate the proposed energy integration. All the load power values are taken in $\mathrm{kW}$.

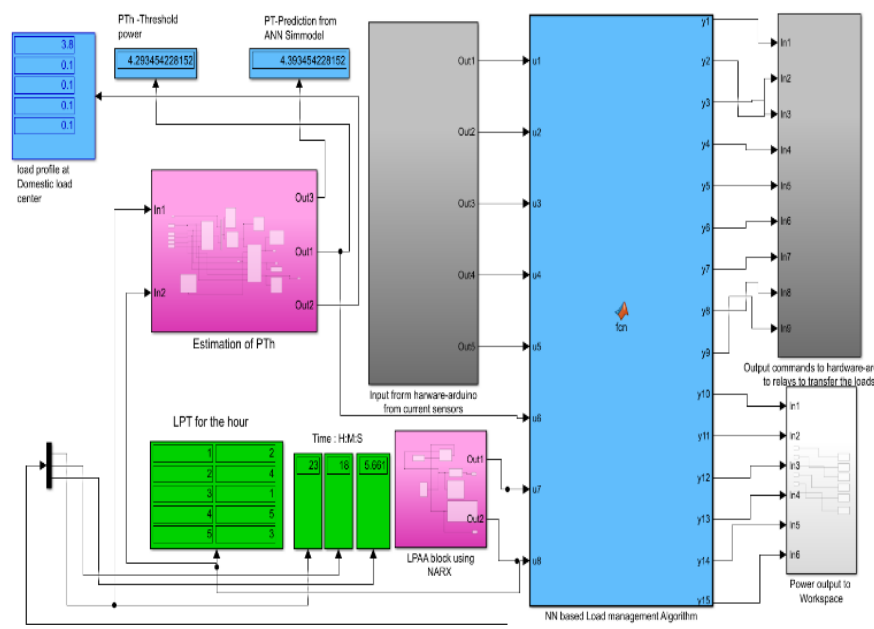

Fig.7. HEMS Simulink Model developed

Simulation is implemented in MATLAB 2018b and run on target hardware: Arduino 2560. Figure 7 presents the Simulink model of HEMS which is embedded on to Arduino using MATLAB-SIMULINK serial communication. LMA block of HEMS takes eight different inputs out of which five inputs are from current sensors through Arduino analog read ports and two are from LPAA block and the last one from block $\mathrm{P}_{\mathrm{Th}}$ estimation block. Figure 8, presents the Simulink block mentioning the Arduino supported input ports with suitable data type conversions. This is input block of the HEMS, which collects the live load data from the real time loads through the current sensors as mentioned above. Data conversion blocks present in it convert the load data to double type for suitability in Simulink environment. Subsequently, live loads read through Arduino pins are taken as inputs to the MATLAB function to execute LMA. As explained in earlier sections, LPAA block presented in figure 9 implements the load priority technique using a MATLAB function to assign priority to all the loads. NARX temperature forecast array $\mathrm{T}_{\mathrm{f}}$ from MATLAB workspace is taken as an input to LPAA block. Once the algorithm assigns the priority LPA table is generated and it is fed to LMA block of HEMS as an eighth input. LPA table is presented in figure 9 .

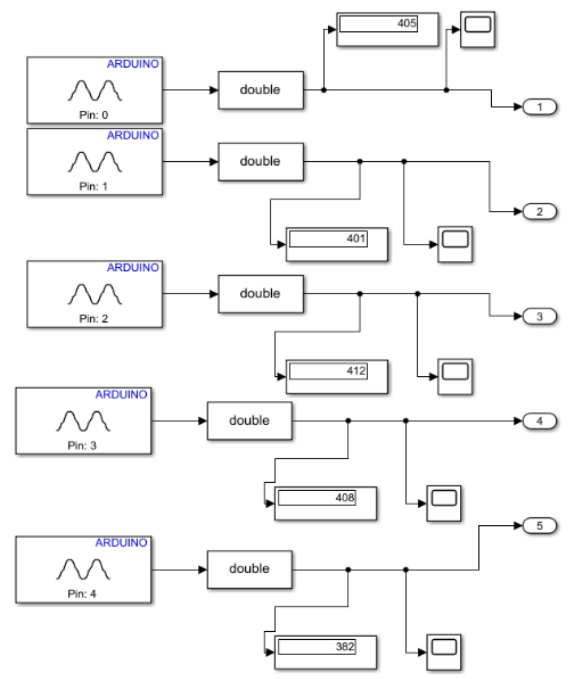

Fig.8. Simulink model of the proposed HEMS

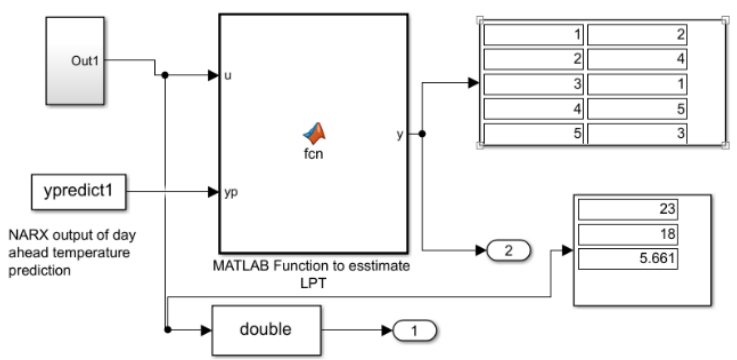

Fig.9. LPAA block with LPA

Simulation block of $\mathrm{P}_{\mathrm{Th}}$ estimation is presented in figure 10 to predict the value of $\mathrm{P}_{T h}$ using a trained feed forward Neural Net, which is trained with six predictor variables of over 8760 samples each. 


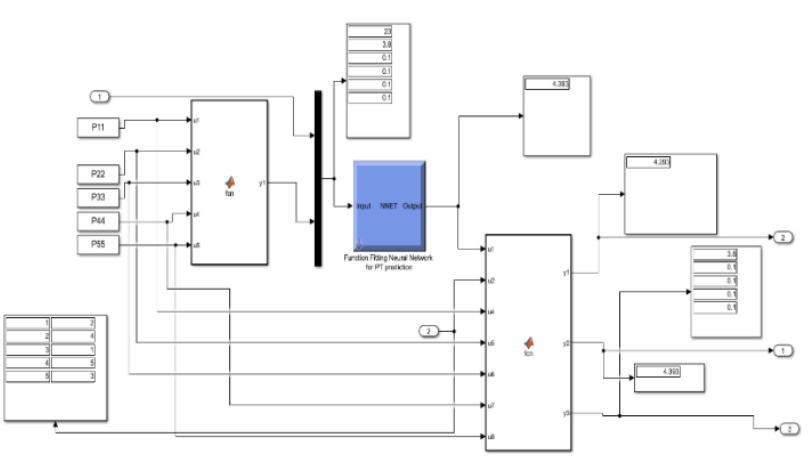

Fig.10. Estimation of $\mathbf{P}_{\text {Th }}$ block

Based on the eight inputs received at LMA block of HEMS, a MATLAB function is developed to execute LMA. As HEMS executes LMA, it sends output signals to the hardware relays through Arduino write ports for switching the loads. It also sends five output signals to the display units and scopes for viewing the output in Simulink environment.

The output block is presented in figure 11, representing nine different relays provisioned at the hardware board.

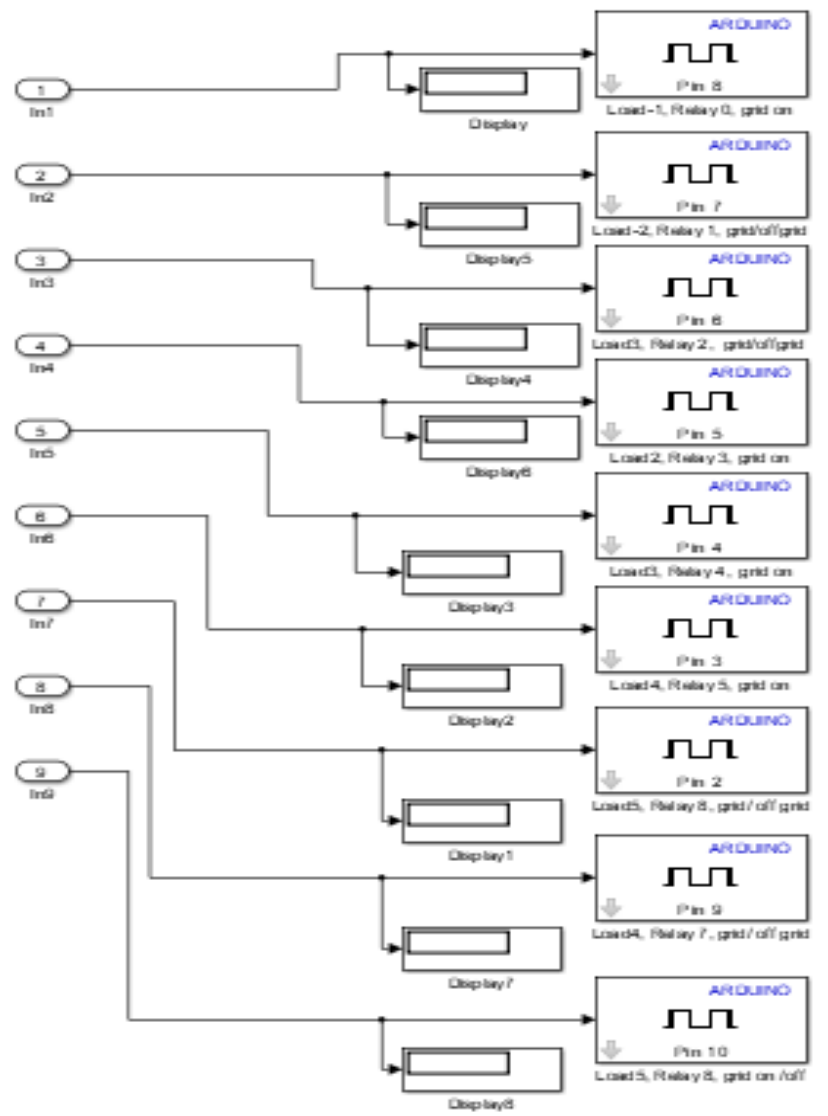

Fig.11. Output block: To trigger the relay hardware

\section{EXPERIMENTAL RESULTS}

The following sections present the results observed at different stages of the HEMS simulation and hardware implementation.

\section{A. Stage 1: Big Data collection and processing}

Historical weather data of three years is retrieved from a weather forecast website and rearranged to train the NARX prediction model. Figure 12 presents three years' temperature time series data of 26280 samples.

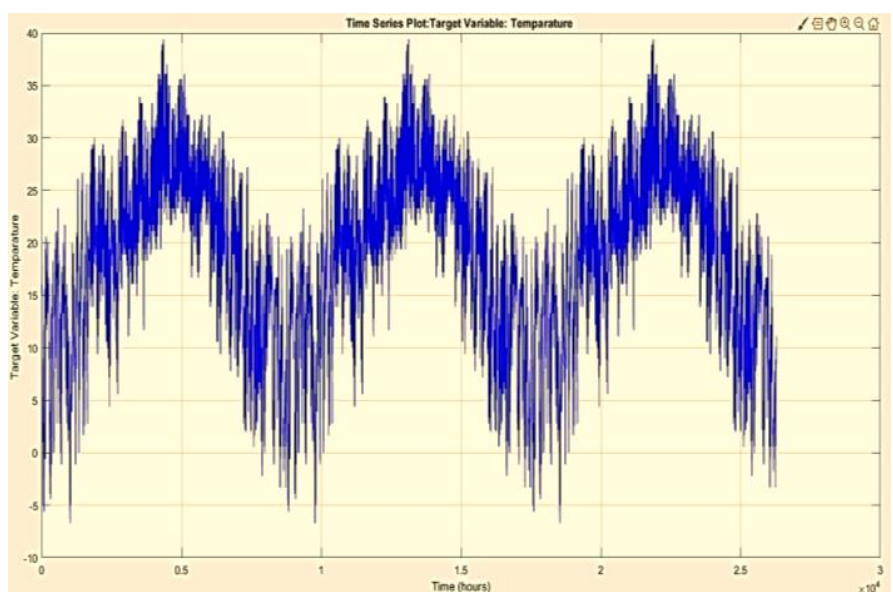

Fig.12. Hourly temperature time series plot

Further, simulated load data of the domestic load center is considered to develop NN model to predict domestic load demand. 8760 samples of five different loads simulated for the load center are considered as predictor variables to train ANN model proposed, for predicting the total power consumption at the load center and are presented in figure 13.

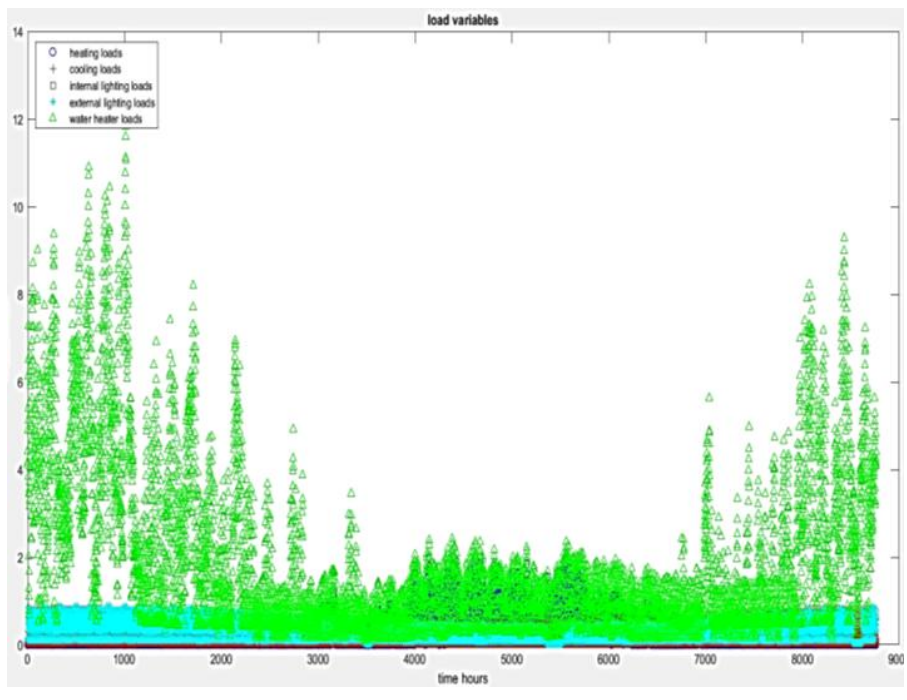

Fig.13. Load profile of five different loads of domestic load center Birmingham Municipality

B. Stage 2: Load Priority Assignment for different appliances of the hour

The LPAA proposed in this paper is customized to assign priority to the loads and allows HEMS to manage loads and DGS by implementing LMA. NARX model is considered to forecast temperature for next 24 hours. NARX net is trained with 5 hidden layers, 6 time stamps of input delays and 6 time stamps of feedback delays. Open loop and closed loop performance of NARX is evaluated and the day ahead prediction of 24 hours' temperature array is obtained through closed loop NARX. Figure 14 presents the regression, output and target graphs to verify the accuracy of the prediction model. NARX model is trained and tested whose details are presented in table 1 .

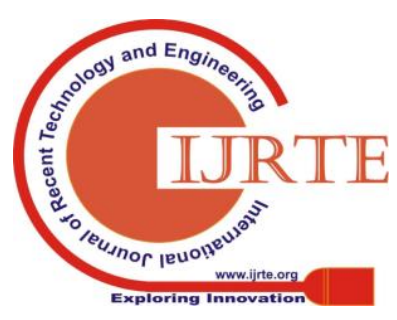




\section{Energy Integration}

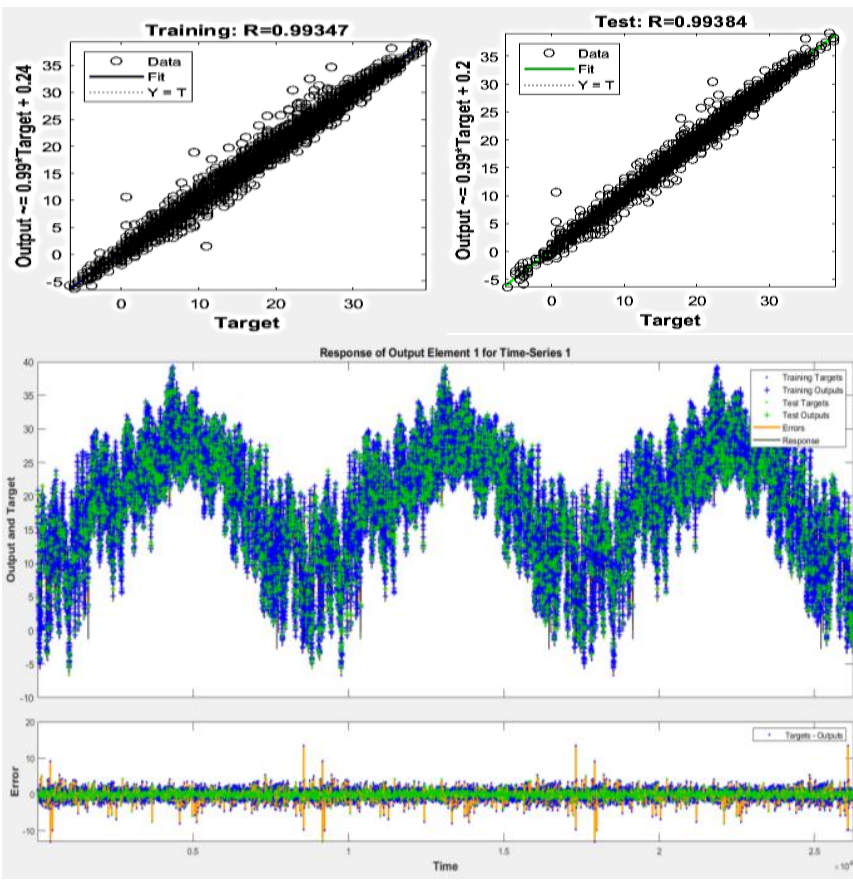

Fig.14. NARX performance plots Table-I: Performance parameters of NARX model

\begin{tabular}{|c|c|c|}
\hline $\begin{array}{c}\text { Performance } \\
\text { parameters }\end{array}$ & MSE & R \\
\hline Training & 0.910845 & 0.993472 \\
\hline Testing & 0.957961 & 0.99384 \\
\hline
\end{tabular}

Forecasted temperature from NARX model is called into a MATLAB function, which customizes LPAA presented in earlier sections. As explained earlier there can be nine possible LPTs, out of which only one LPT results for every hour assigning the priority to all the loads for the particular hour. The LPT results from the LPAA block is marked in figure 15 , for $23^{\text {rd }}$ hour of the day noted while HEMS is operative.

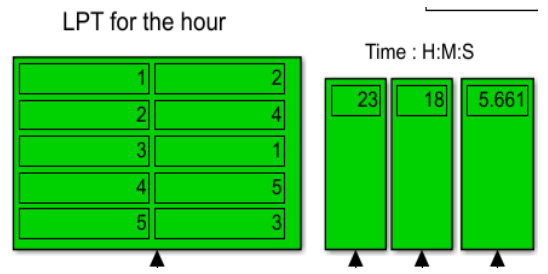

Fig.15. LPT table for the hour from Simulink environment

C. Stage 3: Implementing peak clipping technique: Estimation of $\mathbf{P}_{\mathbf{T h}}$

Estimation of $\mathrm{P}_{\mathrm{Th}}$ is most vital in LMA implementation of HEMS. Equations (1) to (5) are the basis for estimation of $\mathrm{P}_{\mathrm{Th}}$. $\mathrm{P}_{\mathrm{T}}$ present in these equations is the total load demand at the load center, which is proposed to be predicted by big data driven ANN model. So this section presents ANN results and the estimated value of $\mathrm{P}_{\mathrm{Th}}$ in detail. As mentioned in earlier sections, feed forward net is designed with 10 hidden layers using Bayesians regression method to forecast the total power prediction for the hour. 8760 data samples of load variables along with time stamp is concatenated as input matrix of size $(8760 \times 6)$ and 8760 samples of $\mathrm{P}_{\mathrm{T}}$ is considered as target matrix of size $(8760 \mathrm{x} 1)$ to train the feed forward net. Performance parameters of the feed forward NN Model is presented in figure 16 . Regression plot and error histogram shows that, NN fitting is fairly accurate. Target and output variable are also compared and shown in figure 16.

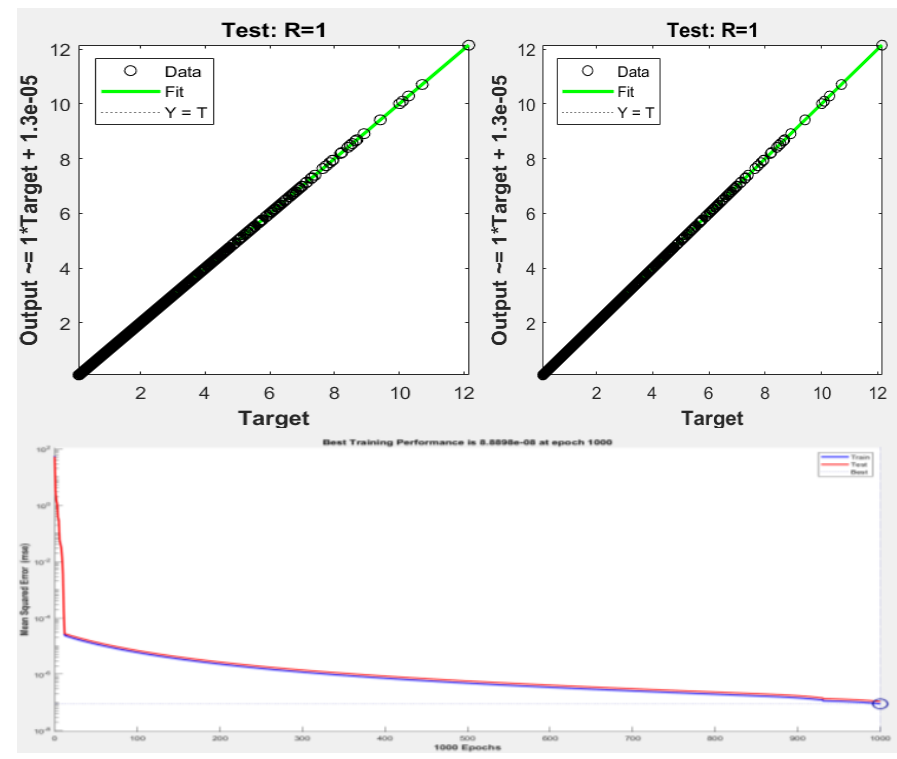

Fig.16. Estimation of $P_{\mathrm{Th}}$ : Performance parameters of NN

To obtain $\mathrm{P}_{\mathrm{T}}$ for any desired hour, input array of six variables is fed to trained Simulink model Net to predict $\mathrm{P}_{\mathrm{T}}$.

Table-II: Performance parameters of feed forward ANN

\begin{tabular}{|c|c|c|}
\hline $\begin{array}{c}\text { Performance } \\
\text { parameters }\end{array}$ & MSE & $\mathbf{R}$ \\
\hline Training & $8.88 \mathrm{e}^{-8}$ & 0.9999 \\
\hline Testing & $1.07 \mathrm{e}^{-8}$ & 0.9999 \\
\hline
\end{tabular}

Out of six variables of input array, five are real time live values of co- load variables read from Arduino analog read ports and the last one is current time generated with time/clock block in Simulink environment. Forecasted $\mathrm{P}_{\mathrm{T}}$ from trained Neural Net is fed to the MATLAB function to calibrate the predicted $\mathrm{P}_{\mathrm{T}}$ to suit to the load capacity connected to the hardware of HEMS. At the end $\mathrm{P}_{\mathrm{Th}}$ is obtained for the hour as per equation 4. Obtained value of $\mathrm{P}_{\mathrm{Th}}$ for $23^{\text {rd }}$ hour of the day is presented in figure 7 while HEMS is operative.

\section{Stage 4: LMA execution towards energy integration}

Results from stage 2 and 3 are taken into the LMA block of HEMS to run the novel LMA towards energy integration. LMA runs as per the flow chart presented in figure 6. LPT from LPAA is considered as an array of LPT. $\mathrm{P}_{\text {Th }}$ from $\mathrm{P}_{\mathrm{Th}}$ estimation block is considered in a single variable array, and real time $\mathrm{P}_{\mathrm{Tn}}$ (total power for the hour at the load center) observed through analog read ports is considered in a single variable array. LMA is implemented with a MATLAB function which runs to compare $\mathrm{P}_{\mathrm{Th}}$ with $\mathrm{P}_{\mathrm{Tn}}$ and sends analog write signals to the relay hardware to transfer the loads between DGSs according to their priority.

During the execution of HEMS, the results obtained at different stages are presented in table 3 and they are hour of the day, predicted temperature from NARX model, Load priority assignment in a table LPT,

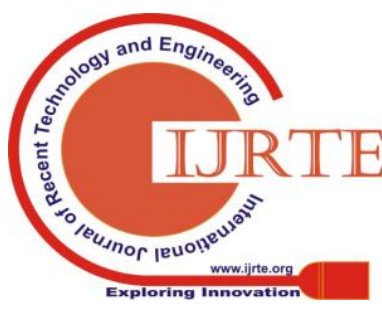


predicted $\mathrm{P}_{\mathrm{T}}$ from $\mathrm{NN}$ model, estimated $\mathrm{P}_{\text {Th }}$ from $\mathrm{NN}$ and the eventual outcome of the LMA about the energy integration through transferring loads between DGSs. The results presented in table 3 are about $23^{\text {rd }}$ hour of the day, where the loads transferring is mentioned in the last column with L5 to DGS2 and remaining to DGS1. This would change consistently as and when the data in first five columns changes.

Table-3: Results at different stages of HEMS

\begin{tabular}{|c|c|c|c|c|c|}
\hline \multirow{2}{*}{$\begin{array}{l}\text { Hou } \\
r \text { of } \\
\text { the } \\
\text { day }\end{array}$} & \multirow{2}{*}{$\begin{array}{l}\text { Temper } \\
\text { ature } \\
\left(\mathrm{T}_{\mathrm{f}}\right) \text { in } \\
{ }^{\circ} \mathrm{C} \\
\text { perditio } \\
\mathrm{n} \text { from } \\
\text { NARX }\end{array}$} & $\begin{array}{ll}\text { LPT from } \\
\text { LPAA } \\
\text { block }\end{array}$ & \multirow{2}{*}{$\begin{array}{l}\mathrm{P}_{\mathrm{T}} \text { in } \\
\mathrm{kW} \\
\text { (Predi } \\
\text { ction } \\
\text { from } \\
\mathrm{NN} \text { ) }\end{array}$} & \multirow{2}{*}{$\begin{array}{l}\mathrm{P}_{\mathrm{Th}} \text { in } \\
\mathrm{kW} \\
\text { Estima } \\
\text { tion }\end{array}$} & LMA execution \\
\hline & & $\begin{array}{l}\text { Load } \\
\text { number- } \\
\text { priority } \\
\text { number }\end{array}$ & & & $\begin{array}{l}\text { Transferring } \\
\text { loads between } \\
\text { DGSs }\end{array}$ \\
\hline \multirow[t]{5}{*}{23} & 3.7 & $\mathrm{~L} 1-2$ & 4.393 & 4.293 & L1: DGS1 \\
\hline & & $\mathrm{L} 2-4$ & & & L2: DGS1 \\
\hline & & $\mathrm{L} 3-1$ & & & L3: DGS1 \\
\hline & & $\mathrm{L} 4-5$ & & & L4: DGS2 \\
\hline & & L5 - 3 & & & L5: DGS1 \\
\hline
\end{tabular}

\section{HARDWARE MODEL OF HEMS}

This section explains on how the hardware is implemented.

Hardware of HEMS is fabricated using simple and cost effective components. Two DGSs considered for the LMA execution are connected through MCBs. Five different loads are considered to be fed from two DGSs. Each load is also connected with a dedicated $\mathrm{MCB}$, to be sure of safe working. DGSs and loads are connected with sensory and relay boards. Real time live power $\left(\mathrm{P}_{\mathrm{Tn}}\right)$ is estimated by a current sensor -ACS 712, with presumed voltage and power factor, hardware proto type of HEMS is presented in Figure 17.

$12 \mathrm{~V}, 5 \mathrm{~A}$ relay boards are used to switch and transfer the loads between DGSs. Simulink facilitates the standalone code generation and runs it on the target hardware. Simulink model presented in figure 7 is run onto the Arduino with proper selection of the simulation settings. There are three different modes that Simulink runs the simulation, out of which the proposed HEMS simulation is run in external mode, to make sure of the working conditions and view hardware responses at the hardware and in the Simulink environment as well.

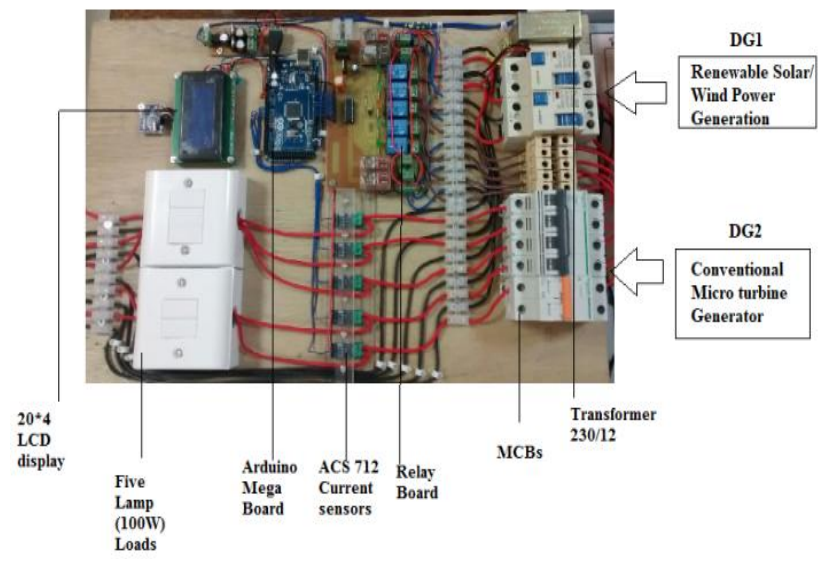

Fig.17. Prototype of proposed HEMS

\section{CONCLUSION}

The proposed model of HEMS with an ability of energy integration is simulated and run on the target hardware to demonstrate its ability. HEMS presented in this paper, works to increase the penetration of nonconventional DGSs over conventional DGSs. Performance indicators and graphs of temperature and total load demand forecast models are presented to ensure the possible accuracy of novel LMA execution. LPT generation and $\mathrm{P}_{\mathrm{Th}}$ estimation is successfully done and possible outcomes for one particular hour is presented in figure 9 and figure 10 respectively. Fabrication of the HEMS using simple and less expensive devices is a breakthrough in energy integration environment. The results presented in table 3 and the LPT table in figure 7 ensure that least priority loads are transferred to nonconventional DGSs and other priority loads are moved to conventional DGSs. Eventually it is proved that the proposed HEMS perform energy integration using NARX and NN prediction models. HEMS presented with an ability of energy integration is quite affordable and accurate to increase the penetration of renewable DGSs for a healthy environment. There is a quite good scope to enhance the ability of energy integration of HEMS by implementing big data driven ML and Deep learning algorithms.

\section{REFERENCES}

1. U.S Energy Information Administration, "Electricpowerannual2010, Table9.4," Nov. 2011 [Online]. http://www.eia.gov/ electricity/ annual/ html/ table9.4.cfm.

2. Gellings CW (1981) "Power/energy: demand-side load management: the rising cost of peak-demand power means that utilities must encourage customers to manage power usage," IEEE Spectr 18(12):49-52.

3. C. W. Gellings, "The concept of demand-side management for electric utilities,” Proc. IEEE, vol. 73, no. 10, pp. 1468-1470, 1985.

4. H. B. Puttgen, P.R. Macgregor, and F.C. Lambert, B "Distributed generation: Semantic hype or the dawn of a new era ?," IEEE Power Energy Mag., vol. 3, no. 1, pp. 22-29, Jan./Feb. 2003.

5. T. Ackermann, V. Knyazkin, B, "Interaction of distributed generation and the distribution network: Operation aspects," in Proc. PES T\&D Conf., Asia Pacific, 2002, vol. 2, pp. 1357-1362.

6. A.J. Dick, S.V. Allera, A.C. Horsburgh, "EMU-The Energy Management Unit," Sixth International Conference on Metering Apparatus and Tariffs for Electricity Supply-1990.

7. H. Farhangi, "The path of the smart grid," IEEE Power Energy Mag., vol. 8 , no. 1 , pp. $18-28$, Jan./Feb. 2010.

8. A. Vojdani, "Smart integration-The smart grid needs infrastructure that is dynamic and flexible," IEEE Power Energy Mag., vol. 6, no. 6, pp. 71-79, Nov./Dec. 2008.

9. P. Wang et al., "Demand side load management of smart grids using intelligent trading/metering/billing system," in Proc. IEEE Power Energy Soc. Gen. Meet., 2010, pp. 1-6.

10. S. Das, D. J. Cook, A. Bhattacharya, I. EO Heierman, and T.-Y. Lin, "The role of prediction algorithms in the MavHome smart home architecture," IEEE Wireless Commun., vol.9, no.6, pp.77-94, Dec. 2002.

11. Qinran Hu, Fangxing Li, "Hardware Design of Smart Home Energy Management System with Dynamic Price Response," IEEE Transactions on Smart Grid, Vol.4, 1878 - 1887, Dec.2013.

12. Vardakas, JS Zobra, N. Verikoukis, C.V, "A survey on demand response programs in smart grids: Pricing methods and optimization algorithms", IEEE communication surveys and tutorials, Volume 4, 152-178, July 2014.

13. Manisa Pipattansomporn, Murat Kuzlu, Saifur Rahman, "An algorithm for intelligent HEM and Demand response analysis," IEEE Transactions on smart grid Vol. 3, 2166-2173, December 2012.

14. Xin Liu; Liviu Ivanescu; Rui Kang; Martin Maier , Real-time household load priority scheduling algorithm based on prediction of renewable source availability",Vol.58, 318-326, July 2012. 
Home Energy Management System for a domestic load center using Artificial Neural Networks towards

\section{Energy Integration}

15. M. Prathap Raju, A. Jayalaxmi, "A Novel Load Management Algorithm for EMU by Implementing Demand Side Management Techniques using ANN," 2017 International Conference on Electrical and Computing Technologies and Applications (ICECTA) , 21-23 Nov. 2017

16. Mahapatra C, Moharana AK, Leung VCM, "Energy management in smart cities based on internet of things: peak demand reduction and energy savings," sensors (Basel) 2017,Dec 5; 17(2). Pii: E2812.

17. Kody M. Powell, Akshaya SriPrasad, Wesley J.Cole, Thomos F. Edger, "Heating, cooling, and electrical load forecasting for a largescale district energy system," Energy, Volume 74, Pages 877-885, September 2014.

18. H.S. Hippert, C.E. Pedreira, and R.C. Souza. "Neural Networks for Short-Term Load Forecasting: A Review and Evaluation," IEEE Transactions on Power Systems, Vol16, 44-55, Feb. 2001.

19. Jukka V. Paatero, Peter D. Lund, "A model for generating household electricity load profiles,” Int. J. Energy Res., vol. 30, no. 5, pp.273290, 2006.

20. Feinberg, E.A., Genethliou, D," Load forecasting," In: Chow, J.H Wu, F.F., Momoh, J.J. (Eds.), Applied Mathematics for Restructured Electric Power Systems: Optimization, Control and Computational Intelligence, Power Electronics and Power Systems. Springer, US, pp. 269-285. 2005.

\section{AUTHORS PROFILE}

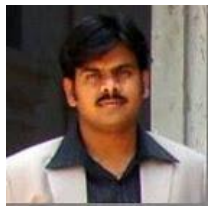

M. Pratapa Raju, received his B. Tech degree, 2003 from G. Pulla Reddy Engineering College and M. Tech (Power electronics) from JNTUH, Hyderabad, $\mathrm{AP}$, India. $\mathrm{He}$ is currently pursuing $\mathrm{Ph}$. $\mathrm{D}$ from JNTUHCE, JNTUH, and Hyderabad- 500085, India His research interests are power electronics, smart grid technologies, artificial Intelligent technics towards future load and supply predictions and IOT based load management systems.

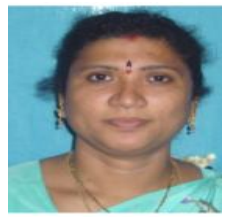

Dr. A. Jaya Laxmi, received her B. Tech degree from NIT Warangal and M. Tech from Osmania University. Awarded $\mathrm{Ph}$. D in the year 2007, from JNTUH, Hyderabad, AP, India. She is currently working as Professor in the Dept. of EEE at JNTUH College of Engineering, JNTUH, Hyderabad-500085, India. Her research interests are Power Systems, Power Quality and Smart Grid Technologies. She has over 232 research papers published in reputed international, national journals and conferences. 